\title{
An Advanced Manufacturing Workshop for Enhancing Engineering and Tech- nology Education
}

\author{
Dr. Richard Chiou, Drexel University (Eng. \& Eng. Tech.)
}

Dr. Richard Chiou is Associate Professor within the Engineering Technology Department at Drexel University, Philadelphia, USA. He received his Ph.D. degree in the G.W. Woodruff School of Mechanical Engineering at Georgia Institute of Technology. His educational background is in manufacturing with an emphasis on mechatronics. In addition to his many years of industrial experience, he has taught many different engineering and technology courses at undergraduate and graduate levels. His tremendous research experience in manufacturing includes environmentally conscious manufacturing, Internet based robotics, and Web based quality. In the past years, he has been involved in sustainable manufacturing for maximizing energy and material recovery while minimizing environmental impact.

Prof. Tzu-Liang Bill Tseng, University of Texas, El Paso

Dr. Tseng is a Professor and Chair of Industrial, Manufacturing and Systems Engineering at UTEP. His research focuses on the computational intelligence, data mining, bio- informatics and advanced manufacturing. Dr. Tseng published in many refereed journals such as IEEE Transactions, IIE Transaction, Journal of Manufacturing Systems and others. He has been serving as a principle investigator of many research projects, funded by NSF, NASA, DoEd, KSEF and LMC. He is currently serving as an editor of Journal of Computer Standards \& Interfaces.

\section{Dr. Michael G Mauk P.E., Drexel University}

Michael Mauk is Assistant Professor in Drexel University's Engineering Technology program.

\section{Dr. Yalcin Ertekin, Drexel University (Tech.) (MERGED)}

Dr. Ertekin received his BS degree in mechanical engineering from Istanbul Technical University. He received MS degree in Production Management from Istanbul University. After working for Chrysler Truck Manufacturing Company in Turkey as a project engineer, he received dual MS degrees in engineering management and mechanical engineering from Missouri University of Science and Technology (MS\&T), formerly the University of Missouri-Rolla. He worked for Toyota Motor Corporation as a quality assurance engineer for two years and lived in Toyota City, Japan. He received his Ph.D. in mechanical engineering from MS\&T in 1999 while he worked as a quality engineer for Lumbee Enterprises in St. Louis, Missouri. His first teaching position was at the architectural and manufacturing Sciences department of Western Kentucky University. He was a faculty at Trine University teaching mainly graduate courses as well as undergraduate courses in engineering technology and mechanical engineering departments. He is currently teaching in Engineering Technology Program at Drexel University. His area of expertise is in CAD/CAM, Computer Numerical Control (CNC) machining, rapid prototyping and quality control. His research interest includes sensor based condition monitoring of CNC machining, machine tool accuracy characterization and enhancement, non-invasive surgical tool design, reverse engineering and bio materials.

\section{Dr. Irina Nicoleta Ciobanescu Husanu, Drexel University (Tech.) (MERGED)}

Irina Ciobanescu Husanu, Ph. D. is Assistant Clinical Professor with Drexel University, Engineering Technology program. Her area of expertise is in thermo-fluid sciences with applications in microcombustion, fuel cells, green fuels and plasma assisted combustion. She has prior industrial experience in aerospace engineering that encompasses both theoretical analysis and experimental investigations such as designing and testing of propulsion systems including design and development of pilot testing facility, mechanical instrumentation, and industrial applications of aircraft engines. Also, in the past 10 years she gained experience in teaching ME and ET courses in both quality control and quality assurance areas as well as in thermal-fluid, energy conversion and mechanical areas from various levels of instruction and addressed to a broad spectrum of students, from freshmen to seniors, from high school graduates to adult 


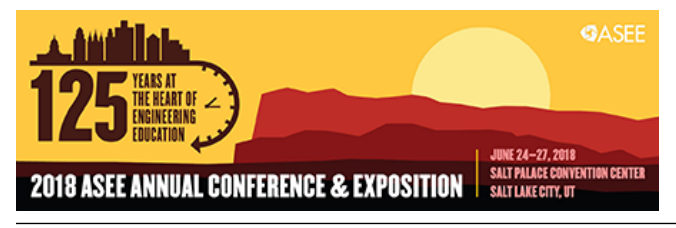

learners. She also has extended experience in curriculum development. Dr Husanu developed laboratory activities for Measurement and Instrumentation course as well as for quality control undergraduate and graduate courses in ET Masters program. Also, she introduced the first experiential activity for Applied Mechanics courses. She is coordinator and advisor for capstone projects for Engineering Technology.

\section{Mr. Carlos Michael Ruiz, Drexel University (Eng. \& Eng. Tech.)}




\title{
An Advanced Manufacturing Workshop for Enhancing Engineering and Technology Education
}

\begin{abstract}
An Advanced Manufacturing Workshop for educators and students to provide current procedures of innovative technology within modern manufacturing practices. The agenda was organized to have presentations from collaborators within industry and academia to address project results on advanced manufacturing, state-of- the-art technologies, and current best practices in industry and education. Attendees conducted focused technical discussions and evaluations on emerging technologies and student needs. The following were the main topics of discussion and events from the workshop: Green Energy Manufacturing, Additive Manufacturing, Digital Manufacturing, Sensor Manufacturing, Robotics-Integrated Manufacturing, Electronics Manufacturing, Surface Engineering, Micro Fabrication, Nano-Manufacturing and Manufacturing Quality Control. Project results on research and education issues in learning for course, curriculum, and laboratory development program were also discussed. The event was organized by faculty and perspective students interested in pursuing a career within engineering. Further collaboration between students and presenters from industry allowed for future communication and interaction of various manufacturing facilities. Such collaboration between presenters from industry, faculty, and students enhances the mobility for engineering education as modern industrial manufacturing facilities and technological procedures/methodologies gain exposure to academia. Student exposure to current techniques and understanding motives for their implementation within the manufacturing industry is important for understanding outcomes of technological aspects as industry seeks to improve manufacturing. The workshop was a 1-day event with an open discussion. Assessments were conducted using information from registrations and post workshop surveys.
\end{abstract}

\section{Introduction}

This paper outlines the results of the workshop on "Advanced Manufacturing Technologies" organized by the Department of Engineering Technology at Drexel University in June 2017. This paper is not confined to summarizing the discussions and conclusions of the workshop, but also elaborates on themes identified at the workshop to substantiate what advanced manufacturing technologies might become in the future. The US Government has set its focus on modern manufacturing that underpins US science strengths and business capabilities. Advanced manufacturing is directly influenced to the advancement of technologies ${ }^{1-2}$. Technology is integrated into manufacturing and becomes essential to companies in within the United States. The progression of techniques continues to be developed in parallel with modern manufacturing methodologies. During the full day event, the emerging areas were discussed. The speakers showcased the latest techniques, findings, applications and utilization of modern manufacturing into specific sectors. Ramping up of production and technological challenges were discussed, along with the commercialization and regulatory constraint.

The presentations were organized in coherence of project results from principal investigators and collaborators from industry and academia on advanced manufacturing, state-of-the-art 
technologies, and modern practices in industry and education ${ }^{3-5}$. The attendees conducted focused technical discussions and evaluations on emerging technologies and student needs. The primary topics of interests for open discussion and events of this workshop included: Green Energy Manufacturing, Additive Manufacturing, Digital Manufacturing, Sensor Manufacturing, RoboticsIntegrated Manufacturing, Electronics Manufacturing, Surface Engineering, Micro-Fabrication, Nano-Manufacturing and Manufacturing Quality Control. Discussed project results from research and education collaborators defined parameters and methodology towards shaping a modern curriculum that upholds current industry standards. The poster illustrated in Figure 1 was designed for students to promote and encourage attendance of this event.

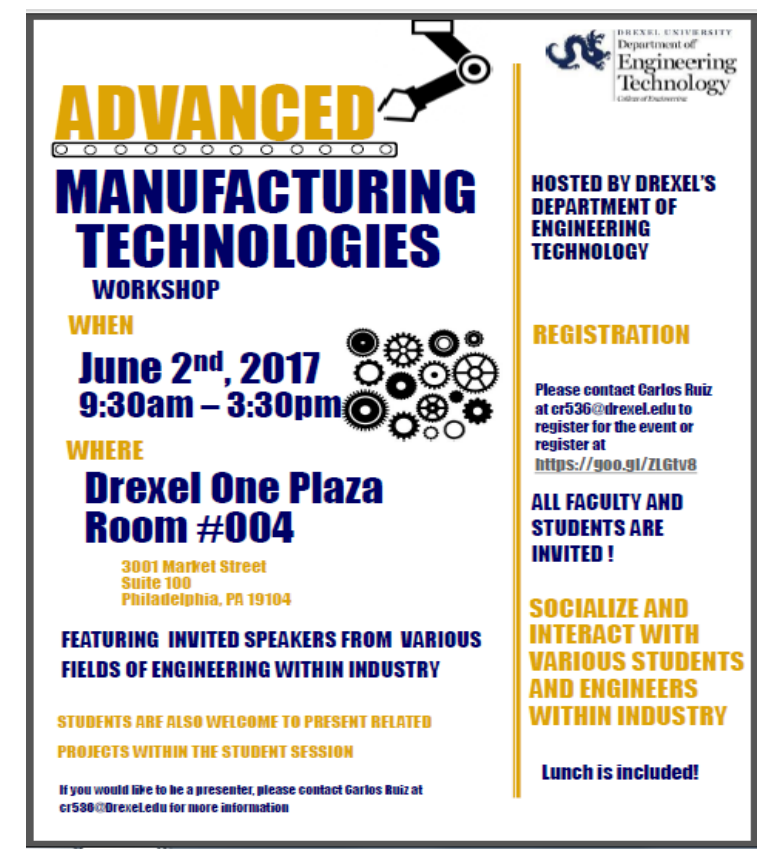

Figure 1. A poster of 2017 Advanced Manufacturing Technologies Workshop

\section{Workshop Series}

The workshop on advanced manufacturing topics was conducted by Drexel University to support and expose engineering students towards cultivating their skills in emerging manufacturing technologies. The workshop was organized and coordinated with the Industrial, Manufacturing, and Systems Engineering Department of the University of Texas at El Paso during the day of $2^{\text {nd }}$ of June, 2017. This workshop explored how the advanced manufacturing technologies not only connects industrial communities, but how they might become responsive characters that engage people and interact with the academic environment in new ways. We seek to address the issues surrounding the integration of emerging technologies with the highly varied assemblies of intelligent emerging technologies that perhaps exist already or will be deployed in them in the near future. The key components of emerging technologies were found in a variety of loosely-related current research areas in the workshop. As shown in Figure 2, a series of technical presentations were implemented to cultivate skills and knowledge of engineering students by exposing advanced manufacturing technologies. 


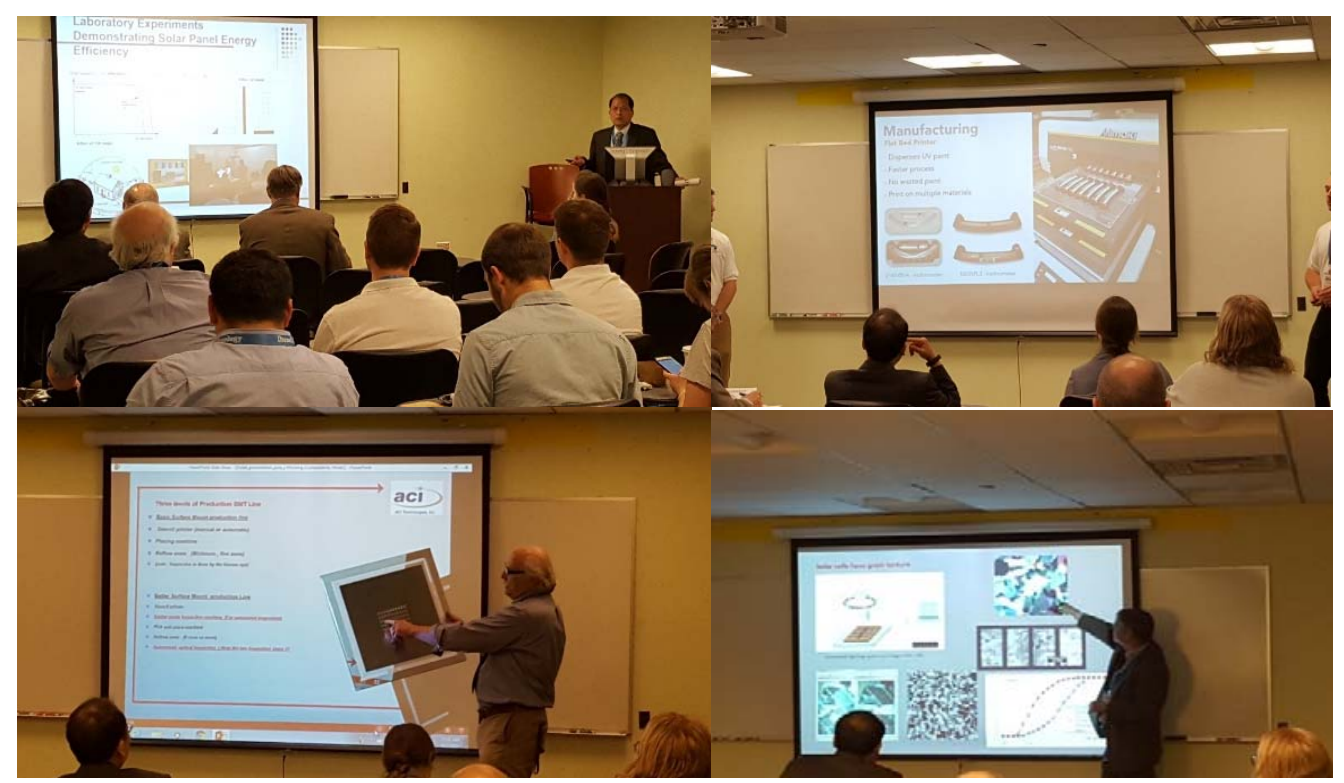

Figure 2. Discussion sessions during the presentations

The following displays the workshop series with the given presenter's title and abstract:

\section{Presentation \#1}

Title: US DoED Green Energy Manufacturing Project Objectives and Results at Drexel University

Abstract: Within the broad paradigm of sustainable manufacturing, the issue of energy efficiency and conservation are addressed specifically in the workshop. We are focusing on increasing the efficiency of energy flows in manufacturing and industrial facilities with certain impact on both economic as well as environmental target variables. Inefficient energy use in manufacturing and industrial facilities is both increasingly expensive and unsustainable. Energy efficiency relates to reducing wasted energy, hence reducing energy consumption. Utilization of fossil fuels adversely affects the greenhouse gases released into the atmosphere and results in undesirable quantities of emissions. Increase energy efficiency will reduce the unwanted environmental effects produced by manufacturing and industrial processes. Controlling energy use is important, but it is also important to assess or estimate it, and to understand methods and approaches for reduction its use and for assessing the cost effectiveness of these measures. The workshop also includes an improvement of resource efficiency as well since these energy flows are typically directly or indirectly connected with the depletion of critical resources (oil, gas, coal). The topic "energy efficiency in manufacturing" is of major relevance from a nation as well as a single company. There is a strong need of appropriate methods and tools to support fostering energy efficiency in manufacturing companies. The student training for manufacturing energy efficiency improvement has become a workforce development initiative for creating the next generation of engineers. The main objective of this workshop aims at contributing towards the improvement of energy efficiency in manufacturing and providing training for undergraduate students in industrial processes, energy assessment procedures, and energy management principles. 


\section{Presentation \#2}

Title: Automated Manufacturing in the Sensor Industry

Abstract: XXXX has been a leader in sensor manufacturing for over 100 years. With an increase in demand for current sensors and the need for more automated and intuitive product solutions, advances in manufacturing have become a key focus in order to satisfy both these needs. This presentation will cover how the advancement and automation of XXXX's manufacturing processes has led to greater effectiveness and efficiency in production of current products, as well as future solutions.

\section{Presentation \#3}

Title: Image Data Mining for Quality Control of Nanofiber Reinforced Piezoelectric Nanocomposites Based on SEM Images

Abstract: Recently, portable and wireless nano-scaled devices have been widely used in environmental monitoring, medical implants, defense technology, industrial safety, and personal electronics, such as the nanowire-based gas and chemical sensors and programmable nanowire circuit for nano-processors. There has been an increasing demand for high energy density capacitors that can be engineered for various applications in advanced devices. In it, piezoelectric nanofiber materials play critical role in producing new products. A piezo-ceramic polymer composite contains a polymer of high dielectric strength and high permittivity ceramic inclusions, making it well suited as a high energy density capacitor. Furthermore, the research shows that the well aligned piezoelectric nanofibers generate better dielectric permittivity performance than random distributed ones. Hence, how to evaluate the nanofiber alignment for quality control becomes very critical. However, the extremely small size of nanofiber makes the quality control evaluation process very difficult. Currently, the standard quality inspection technique is the morphology analysis of nanofibers embedded in the base material based on microscopic images, e.g., scanning electron microscope (SEM) images. Visual checking of these SEM images is often adopted to evaluate the nanofiber alignment, which is often subjective, inaccurate and timeconsuming. Therefore, how to automatically extract the nanofibers (number, sizes, locations and orientations) is highly desirable. The objective of this research is to fill such need by developing various image data mining methods for automatically nanofiber alignment evaluations through the SEM images. These image data mining methods are proposed to extract the information of the nanofibers through SEM images. The first method use a series of image processing algorithms (thinning, windowing, transforming and convolution process) to get the probability distribution to find the orientation of the nanofibers in SEM images. Second method use Hough transform based algorithms to segment the nanofibers from SEM images. The third method use a statistics method (cost function based multiple change points method) base on the boundary data of the nanofibers to extract the parameters (size, location, orientation) of nanofibers in SEM images. Finally, through the comparison of these image data mining methods, the advantages and weak points of each method can be summarized to help people improve them in future quality control results.

\section{Presentation \#4}

Title: Modern Electronics Manufacturing 
Abstract: The electronics industry is continuing to advance around the twin channels of design and manufacturing. As designers drive to pack more capability into products and make them smaller, faster, and more capable, so the manufacturing equipment and knowledge must devise ways to keep pace with these advances. This presentation will be covered in two stages, first there will be presentation describing the state of the art in electronics assembly manufacturing, and current best practices. This creates a base line of knowledge. Building on the first stage, the second part of the presentation will discuss current advances in manufacturing processes and equipment, specifically high speed Optical inspection and 3D Computerized Tomography for the programmable components. A look into the future will be covered.

\section{Presentation \#5}

Title: Surface Characterization Methods for Modern Manufacturing

Abstract: Surfaces of materials play a key role in many technologies ranging from semiconductor devices, to optical components, to medical implants, to machined metal parts. Surface features and characteristics determine optical properties (reflection and light scattering), adherence of coatings, susceptibility to contamination and corrosion, wear, friction and lubrication, sealing, thermal contact, wetting properties, and appearance. Engineering of surfaces is important in solar cells, fluidic systems, MEMS, and optics; and poor surface quality is a major limitation of many rapid prototyping methods such as $3 \mathrm{~d}$ printing and laser machining. We are making a systemic comparison of many methods for surface characterization including: surface profiling with a stylus, atomic force microscopy (AFM), white light interferometry, laser and LED scattering, wetting angle measurements, and image processing. We focus on three applications areas: silicon solar cells in various stages of manufacture, machined metal components, and 3d-printed plastic parts. We discuss informational content, speed of measurements, and automation of these techniques.

\section{Presentation \#6}

Title: Characterization and Quality Assessment of Shape Memory Polymer Parts Fabricated Using Fused Deposition Modelling

Abstract: To date, a Shape Memory Polymer (SMP) part is considered a part that after a high degree of deformation is capable to recover partially or totally its original shape by applying external stimulus sources like thermal, light, magnetics. This research aims to characterize the Tensile strength mechanical properties of 3D printed SMP parts and obtain recovery ratios after a thermo-mechanical cycle. In addition, this research will focus on performing quality evaluation through implementing Design of Experiments (DOE). Consequently, main effect plot and iteration plot in ultimate tensile strength are presented. Further, the part dimensional accuracy distribution is obtained by comparing 3D scan model of a produced part with the actual model. Also, dimensional accuracy evaluation is presented comparing the 3D scan model of the produced part with a 3D scan model of the recovered when suffered a high degree of deformation. This paper is a reference for process control of SMP parts produced using Fused Deposition Modelling (FDM) and for evaluation approaches for quality assessments of dimensional accuracy. 


\section{Presentation \#7}

Title: Qualification for Industry 4.0

Abstract: Industry is undergoing fundamental change. After mechanization, industrialization and automation, it has now reached the threshold of the fourth revolution: digitization and networking. The manufacturing processes used in factories today are being rendered more productive, more intelligent, more controllable, and more transparent. Industrial processes will be networked with each other, incorporating modern communication and information technologies to create enduring improvements in the production process. With the help of these new digital production methods, companies will be able to respond to individual customer requirements more easily, sharpening their competitive edge in global markets. These advanced trends in production will not only affect technical industrial processes, but even more so, the workers in these factories. People and technology will be more interconnected in complementary ways. Ensuring the skills evolution of qualified personnel and junior employees for current and future changes in the workplace is paramount. These changes will require employees who are 4.0 specialists and possess interdisciplinary skills uniting classic mechatronics qualifications with sound IT knowledge and high levels of social competence.

\section{Presentation \#8}

Title: Manufacturing Engineering for the Digital Age

Abstract: Manufacturing Engineering in the Digital Age will span the entire product life cycle, from Design to Build to long-term Product Support. This talk will walk through the manufacturing engineering process from start to finish of manufacturing of a particular flight critical component of a commercial helicopter from YYYY, a ZZZZ company, to highlight the complex materials and processes, engineering tasks, and tooling spanning initial technology concept development to full rate production of product. It will wrap up with a discussion of five key drivers of future commercial and defense air vehicle manufacturing.

\section{Presentation \#9}

Title: Advances in Manufacturing Technologies embedded into ET curricula: Impact of Manufacturing Design and Simulation Tools on Senior Capstone projects

Abstract: As global economies are moving towards decreasing their carbon footprint, the use of renewable energy resources as the likely alternative is boosting. Manufacturing industries are adapting to sustainable processes and products while enhancing the use of green energy alternatives. The educational counterpart should keep the pace with the demand of trained professionals in these areas. The desired set of skills required of modern engineers and technologists has been steadily expanding. In addition to familiarity with a number of manufacturing processes and CAD/CAM techniques, various process simulation tools are increasingly becoming an essential tool in the design and manufacturing of complex systems. Our task as educators in the engineering realm is to prepare students to be more effective in a global context as well as to be able to respond to today's challenges, giving them the essential 
competencies for global engineering work. We will present the contribution of learning-bydiscovery industry-integrated ET curriculum to competency-based education in sustainable manufacturing and green energy. In this presentation, the integration of Material Selection as well as Moldflow and SolidWorks plastics tools in traditional manufacturing processes course is presented. SolidWorks plastics Standard brings easy-to-use injection molding simulation directly to the designers of plastic parts and injection molds, as well as advanced CAE analysis. It simulates how melted plastic flows during the injection molding process to predict manufacturing-related defects on parts and molds. Students can quickly evaluate manufacturability during design process, to eliminate costly mold rework, improve part quality, and accelerate time to market with minimal lead time. Similar to SolidWorks plastics, Moldflow software also provides simulation tools for injection mold design, plastic part design, and the injection molding design process. In the Manufacturing Processes course, laboratory and term project activities are being developed and used to promote creativity and critical thinking, a place where students develop, practice and improve the required skills using modern tools, and a place where theory meets the real-like scenarios. Capstone projects developed in the past five years by our students are the corollary of their educational journey and also an excellent assessment of their level of skills and competencies acquired during this journey. The main aspects presented are related to the integrative approach in sustainable process and product design, with a clear assessment of student-led projects developed during past AYs and how they contributed directly to development of leadership skills along with untamed creativity.

\section{Assessment of Workshop}

The workshop was held by Drexel University. Eleven participants gave their assessment of the workshop. Online registration was monitored to determine the concentrations that took notice of the event and registered to attend. It is clear from the results within Appendix A that senior and junior students within the fields of mechanical, industrial, and electrical engineering were predominantly interested in attending the event. The concentrations least interested in attending were students within the areas of Business and Project Management.

The overall effectiveness of the workshop was determined by a given scale. The survey can be seen in scale was a direct evaluation of the workshop. The scale was from 1-4 (Not Needed Essential). According to results shown in Table 1 within Appendix B of the given survey, the workshop was successful to "disseminate what advanced manufacturing is and its impact to the future of US" and to "develop strategies for measuring quality for design and advanced manufacturing". The results showed these two responses were the highest rated within the evaluations with a standard deviation of 0 . The lowest mean from the survey was given by responses from question \#6, which stated "promote the progress of technologies as strong applications in manufacturing". The deviation for this response was 0.6. Some students also provided feedback within the response portion of the survey with statements such as "Very Good", "More time with presenters", "very fascinating and informative session", and "Wow I really learned so much from industry". An enrolled student attending the workshop gave a written response to workshop collaborators in which the student stated the following:

"... a realization that the program I have enrolled in will help me achieve the position I want to see myself in future. I was happy to see that various concepts that we were learning in our course 
work such as stress to strain curve, pick and place robot and even the profilometer being readily used in the real-world application. The part that the presenters as well as the faculty were questioning and sharing ideas was a very welcome experience for me as I could discern the various layers of a certain topic that I myself wouldn't have been able to question and comprehend. The workshop was a very genuine experience for me as it provided a window to peek at what lies ahead for me."

\section{Conclusion}

The industrial presenters were able to discuss freely with students and faculty various and new methodologies within manufacturing. Students shared information and were able to establish a social network with industrial partners as some students obtained contact information. The conversations led to students having access for tours and machinery with industry presenters. This was displayed as an important communicative line from education and industry as discussion was exchanged. One student stated she enjoyed the workshop, but she would have like to have had an extended lunch period with the faculty and industrial partners for continued discussions. Overall feedback from students were positive as students have also asked for a schedule of the next event with industrial partners for Advanced Manufacturing. Suggestions focused on obtaining more time to communicate with faculty and industrial partners. This can be improved with extended scheduled breaks between presentations to allow students and presenters more time for open discussion after the response session. The event displayed the necessity of communication between education, research and industry to prepare students for a career within manufacturing.

\section{Acknowledgement}

The authors of this paper would like to thank the Department of Education (Grant No: Award P031S120131) for its financial support towards the project.

\section{REFERENCES}

1. David L. Bourell, University of Texas at Austin; Sudarsanam Suresh Babu, University of Tennessee-Knoxville; Jack Beuth, Carnegie Mellon University; and James W. Sears, GE Global Research Center, Additive Manufacturing Materials and Processes Workshop, TMS Materials Processing \& Manufacturing Division (MPMD), Structural Materials Division, and Powder Materials Committee, Music City Center, Sunday, February 14, 2016, 1:00 p.m. to 5:30 p.m. (CST)

2. Sundaresan Jayaraman, Kolon Professor, Kolon Center for Lifestyle Innovation, Workshop on Advanced Materials for Additive Manufacturing (3D Printing): State-of-Art, Challenges and Opportunities, Georgia Tech Manufacturing Institute, September 28, 2017.

3. Richard Chiou, Tzu-Liang Bill Tseng, Irina Nicoleta Ciobanescu Husanu, Carlos Michael Ruiz, Smarth H. Chadha, Shraman Kadapa, “A Workshop for Integration of Internet of Things into Green Energy Manufacturing,” the 124th Annual Conference \& Exposition, June 25 - 28, 2017, Columbus, Ohio.

4. Tzu-Liang Bill Tseng, Aditya Akundi, Arturo Olivarez Jr., and Richard Chiou, "Workshops and Seminar Series to Enhance and Create Opportunities for Innovation in Green Manufacturing and Engineering," the 124th Annual Conference \& Exposition, June 25 - 28, 2017, Columbus, Ohio.

5. Tzu-Liang Bill Tseng, Richard Chiou, Radian G. Belu, Oscar H. Salcedo, Aditya Akundi, Eric D. Smith, "Enhancement of Green Energy Manufacturing Engineering Education Through Project-based Learning and 
Leadership Workshops,” American Society for Engineering Education (ASEE) in Indianapolis, Indiana for the 122nd Annual Conference \& Exposition, June 14 - 17, 2015. Seattle, WA, USA.

6. Garcia, M., Numers, Stephanie von, and Twamley, Erin (2014, May 8). Educated and Equipped: Energy \& Manufacturing Training. Office of Energy Efficiency and Renewable Energy, U.S. Department of Energy. Retrieved January 23, 2015. 
Appendix A:

ADVANCED MANUFACTURING TECHNOLOGIES

\section{ADVANCED MANUFACTURING TECHNOLOGIES}

Event Address: 3001 Market Street Philadelphia, PA Suite 100 Room \#4

- Required

\section{REGISTRATION}

Please complete the following form.

If you should have either any questions or concerns, please contact Carlos

1. First, Last Name:

2. Email Address: *

3. Please select one of the following that applies to you: "

Mark only one oval

Freshmen

Sophomore

Junior

Senior

Faculty

Graduate

Other:

4. What is your major? *

FIGURE A-1 REGISTRATION FOR WORKSHOP 


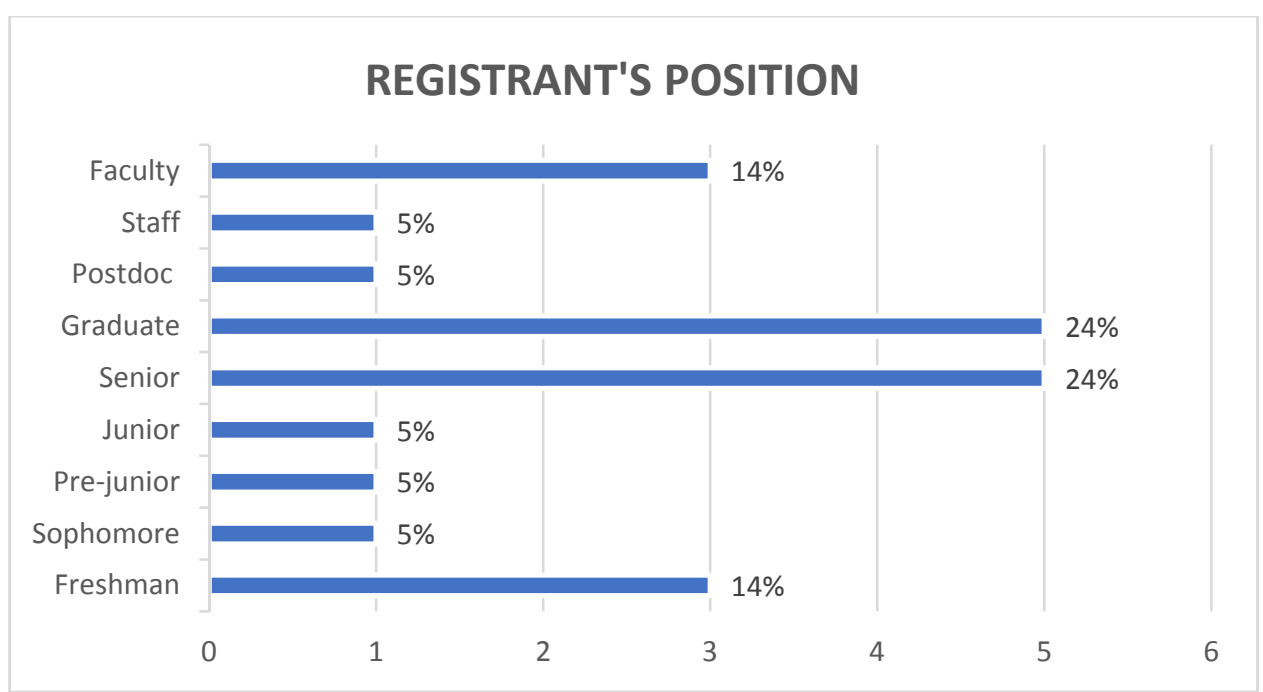

FIGURE A-2 REGISTRANT'S LEVEL OF EDUCATION

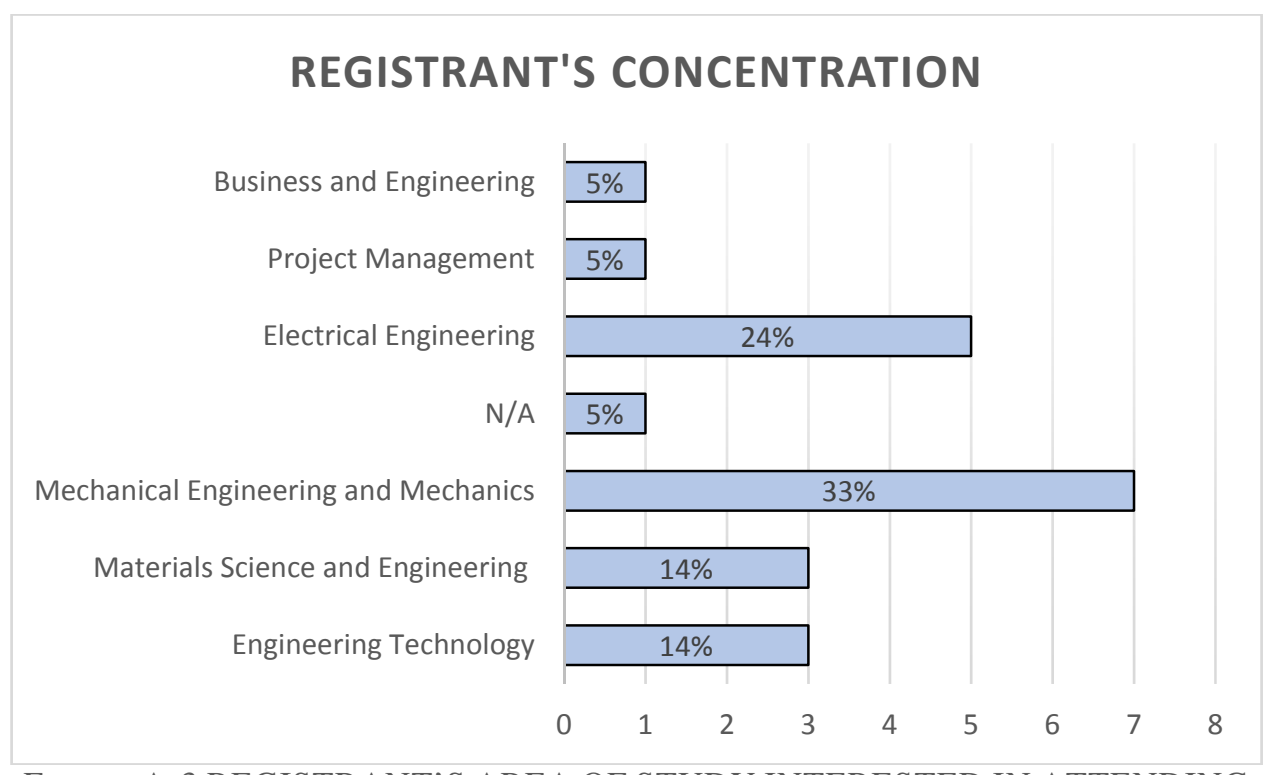

FIGURE A-3 REGISTRANT'S AREA OF STUDY INTERESTED IN ATTENDING 
Appendix B:

\begin{tabular}{|c|c|c|c|c|c|}
\hline 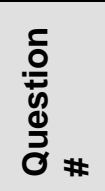 & 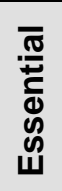 & $\frac{\overline{\frac{3}{2}}}{\frac{0}{\frac{0}{0}}}$ & 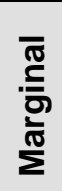 & $\begin{array}{r}\frac{\partial}{8} \\
\frac{d}{d} \\
\text { d }\end{array}$ & Feedback Events and Material \\
\hline & & & & & Objectives of the Workshop for 2017 \\
\hline 1 & & & & & $\begin{array}{l}\text { Disseminate what advanced manufacturing is and its impact } \\
\text { to the future of US }\end{array}$ \\
\hline 2 & & & & & $\begin{array}{l}\text { Address manufacturing roles in industry and strategies on its } \\
\text { integration with technologies }\end{array}$ \\
\hline 3 & & & & & $\begin{array}{l}\text { Investigate the implementation of technologies into } \\
\text { manufacturing based on the needs of the industry }\end{array}$ \\
\hline 4 & & & & & $\begin{array}{l}\text { Establish a networking infrastructure with other universities } \\
\text { and industrial partners for advanced manufacturing }\end{array}$ \\
\hline 5 & & & & & $\begin{array}{l}\text { Promote the progress of technologies as strong applications } \\
\text { in manufacturing }\end{array}$ \\
\hline 6 & & & & & $\begin{array}{l}\text { Address how technology professional development } \\
\text { programs can achieve goals in manufacturing }\end{array}$ \\
\hline 7 & & & & & $\begin{array}{l}\text { Develop strategies for measuring quality for design and } \\
\text { advanced manufacturing }\end{array}$ \\
\hline 8 & & & & & $\begin{array}{l}\text { Build successful curricula and programs based on the needs } \\
\text { of the industry }\end{array}$ \\
\hline 9 & & & & & $\begin{array}{l}\text { Broaden participating partners from universities, industry, } \\
\text { colleges, and communities }\end{array}$ \\
\hline
\end{tabular}

FIGURE B-1 WORKSHOP SURVEY

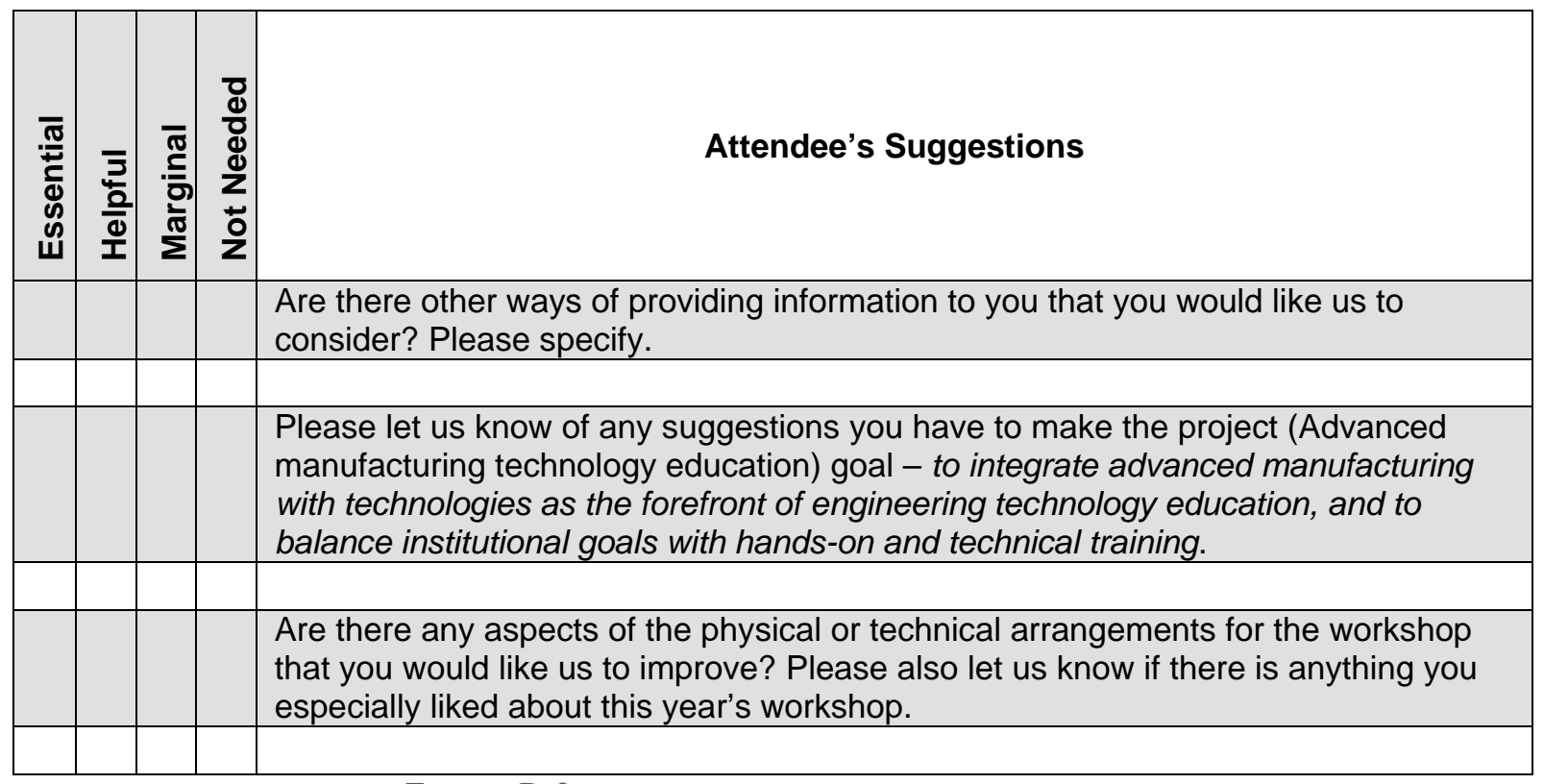

FIGURE B-2 WORKSHOP SURVEY: OPEN ENDED SECTION 
Table 1: Mean and Standard Deviation for Survey

\begin{tabular}{|l|l|l|}
\hline $\begin{array}{l}\text { Question } \\
\#\end{array}$ & Mean & $\begin{array}{l}\text { Standard } \\
\text { Deviation }\end{array}$ \\
\hline 1 & 4.00 & 0.00 \\
\hline 2 & 3.11 & 0.78 \\
\hline 3 & 3.67 & 0.50 \\
\hline 4 & 3.33 & 0.50 \\
\hline 5 & 2.89 & 0.60 \\
\hline 6 & 3.33 & 0.50 \\
\hline 7 & 4.00 & 0.00 \\
\hline 8 & 3.56 & 0.53 \\
\hline 9 & 3.33 & 0.50 \\
\hline
\end{tabular}

